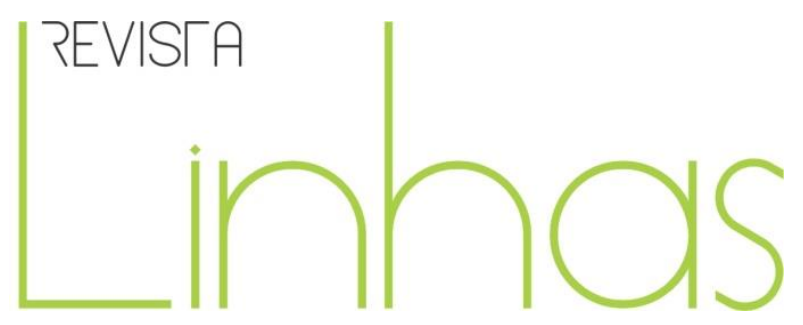

\title{
Atendimento Educacional Especializado na modalidade domiciliar: funcionamento e organização
}

\begin{abstract}
Resumo
Este artigo tem como objetivo analisar o funcionamento e organização do Atendimento Educacional Especializado na modalidade domiciliar, conforme operacionalizado em uma rede municipal de ensino. O Atendimento Educacional Especializado principal serviço da área de Educação Especial em nosso país, conforme a atual Política de Educação Especial na Perspectiva da Educação Inclusiva (SEESP/MEC, 2008) e diversos documentos orientadores e legislativos - vem sendo objeto de inúmeros estudos. Contudo, uma de suas modalidades, a domiciliar, ainda requer maior aprofundamento. O estudo de campo foi estruturado a partir dos pressupostos da pesquisa-ação. Os dados foram construídos a partir dos registros em diário de campo, entrevistas e videogravação de três anos de intervenção nessa modalidade. Nossas análises apontam para a necessidade de: formação docente que contemple a diversidade e as implicações desse tipo de atendimento; reorganização escolar para o funcionamento dessa prática, articulando 0 trabalho do professor da Educação Especial, responsável pelo Atendimento Educacional Especializado, com o do ensino comum e os demais educadores da escola; estabelecimento de uma parceria com a família; e, a elaboração de instrumentos que orientem a prática pedagógica do professor, como o Planejamento Educacional Individualizado.
\end{abstract}

Palavras-chave: Atendimento Educacional Especializado;; Organização e Funcionamento; Educação Especial; Educação Inclusiva.

\author{
Annie Gomes Redig \\ Universidade do Estado do Rio \\ de Janeiro - UERJ - RJ/Brasil \\ annieredig@yahoo.com.br
}

Flávia Faissal de Souza

Universidade do Estado do Rio de Janeiro - UERJ - RJ/Brasil faissalflavia@gmail.com

\section{Para citar este artigo:}

REDIG, Annie Gomes; SOUZA, Flávia Faissal de. Atendimento Educacional Especializado na modalidade domiciliar: funcionamento e organização. Revista Linhas. Florianópolis, v. 17, n. 35, p. 68-86, set./dez. 2016. 


\title{
Specialized Educational Services at home: operation and organization
}

\begin{abstract}
This article has the objective to analyze the operation and organization of the Specialized Educational Services at home, as operated in an Municipal Education Network. The Specialized Educational Services - main service in the special education area in our country, as an policy of the Special Education in an Inclusive Education perspective (SEESP/MEC, 2008) and many guiding and legislative documents - has been objet of countless studies. However, one of its modes, the home, still requires more deepening. The field study was structured from the assumption of the action research. The data was built from daily registers on the field, interviews and filming of tree years of interventions in this modality. Our analysis point to the need of: teacher formation that contemplate the diversity and implications of this kind of attendance: school reorganization for this practice to work, articulating the work of the special education teacher, responsible for the Specialized Educational Services, with the regular teaching and the other educators of the school; establishment of a partnership with the family; and elaboration of instruments that guide the pedagogical practice of the teacher, like the Individualized Educational Planning.
\end{abstract}

Keywords: Specialized Educational Services; Organization and Operation; Special Education; Inclusive Education. 


\section{Introdução}

A ideia do Atendimento Educacional Especializado, embora hoje tenha outro estatuto, há muito está presente no escopo das políticas e da legislação, definido como o suporte advindo do trabalho educacional específico às necessidades educacionais dos alunos. Encontramos essa ideia em diversos documentos legais que nos contam um pouco dessa história, entre esses: Constituição de 1988 (BRASIL, 1988); Política Nacional de Educação Especial de 1994 (SEESP/MEC, 1994); LDBEN nº. 9.394, de 1996 (BRASIL, 1996); e, Resolução CNE/CEB n. 2, de 2001 (CNE/CEB/BRASIL, 2001). Frente ao conceito atual, estes documentos trazem uma ideia mais ampla, assumindo o Atendimento Educacional Especializado como substitutiva ao ensino comum. Não só em documentos, mas ainda existem redes de ensino que assumem este conceito de forma mais ampla.

O Atendimento Educacional Especializado (AEE) atualmente é mais difundido por ser o serviço que representa a Educação Especial. Como todos sabemos, o AEE é oferecido no contraturno, de forma complementar e/ou suplementar, cujo objetivo central é a acessibilidade ao conhecimento. Ou seja, diferente de outros serviços de apoio pedagógico, a ideia é que no AEE o aluno possa aprender a aprender (SEESP/MEC, 2008; CNE/CEB/BRASIL, 2009; BRASIL, 2011, entre outros).

No escopo das formas de oferecimento do AEE, esse estudo trata do Atendimento Pedagógico Domiciliar (APD). Pautado na ideia que a educação é um direito de todos Declaração Universal dos Direitos Humanos da ONU de 1948; Convenção sobre os Direitos das Crianças da ONU de 1990; Constituição Constituição da República Federativa do Brasil de 1988; Estatuto da Criança e do Adolescente do Brasil de 1990; LDBEN 9.394 de 1996-, o intuito do APD é

elaborar estratégias e orientações para possibilitar o acompanhamento pedagógico-educacional do processo de desenvolvimento e construção do conhecimento de crianças, jovens e adultos matriculados ou não nos sistemas de ensino regular, no âmbito da educação básica e que encontram-se impossibilitados de freqüentar escola, temporária ou permanentemente e, garantir a manutenção do vínculo com as escolas por meio de um currículo flexibilizado e/ou adaptado, favorecendo seu ingresso, retorno ou adequada integração ao seu grupo escolar correspondente, como parte do direito de atenção integral. (BRASIL. SEESP/MEC, 2002, p. 05) 
Embora o APD esteja relacionado a toda educação básica, no nosso caso, o APD está inserido no escopo do AEE por se tratar de uma análise de dados construídos a partir de um trabalho de escolarização desenvolvido com uma aluna com deficiência múltipla. Redig (2015) já explorou alguns aspectos deste trabalho de campo e, dadas algumas peculiaridades desse serviço, nos chama atenção para como devemos olhar com mais cuidado para a estrutura e o funcionamento do mesmo, considerando as diretrizes políticas e o papel da escola na construção do processo de escolarização dos alunos que não podem frequentar o colégio, "respeitando o seu direito à educação e oferecendo o atendimento pedagógico domiciliar, como uma alternativa para a continuidade do ensino ou como a única forma de acesso à educação" (REDIG, 2015, p. 68).

Isto posto, o objetivo deste estudo foi analisar o funcionamento e organização do Atendimento Educacional Especializado na modalidade domiciliar, conforme operacionalizado em uma rede municipal de ensino. Sendo assim, apresentaremos um estudo de caso de uma aluna com deficiência múltipla, o planejamento e desenvolvimento do APD. Para tal, foi necessária a construção de um Plano Educacional Individualizado com a finalidade de elencar as dificuldades e habilidades da estudante, para então, traçar as estratégias e metas necessárias para o processo de ensinoaprendizagem.

\section{AEE e APD: aspectos políticos, legislativos e pedagógicos}

Como afirmamos acima, o Atendimento Educacional Especializado é garantido, em um sentido mais amplo, desde a década de 80 do século passado. Como sabemos, já no capítulo sobre a Educação Especial na LDBEN n 9.394, de 1996 (BRASIL, 1996) é afirmado que, tendo como foco os alunos público-alvo da Educação Especial, matriculados preferencialmente na rede regular de ensino "Haverá, quando necessário, serviços de apoio especializado, na escola regular, para atender às peculiaridades da clientela de educação especial”. Sendo que: “O atendimento educacional será feito em classes, escolas ou serviços especializados, sempre que, em função das condições específicas dos alunos, não for possível a sua integração nas classes comuns de ensino regular”. Sendo 
previsto, entre outros, professor especializado e "currículos, métodos, técnicas, recursos educativos e organização específicos, para atender às suas necessidades”.

Ainda nesse mesmo documento, embora não seja citado no capítulo específico sobre a Educação Especial, no Título III, “Do direito à educação e do Dever de Educar”, podemos encontrar os fundamentos para o oferecimento do APD. Já no Art. $5^{\circ}, \S 5^{\circ}$, é afirmado que "Para garantir o cumprimento da obrigatoriedade de ensino, o Poder Público criará formas alternativas de acesso aos diferentes níveis de ensino, independentemente da escolarização anterior”. E, mais, no Art. 23, do Título V, "Dos Níveis e das Modalidades de Ensino", Capítulo II: Educação Básica, Disposições Gerais, encontramos: “A educação básica poderá organizar-se em séries anuais, períodos semestrais, ciclos, alternância regular de períodos de estudos, grupos não-seriados, com base na idade, na competência e em outros critérios, ou por forma diversa de organização, sempre que o interesse do processo de aprendizagem assim o recomendar" (grifo nosso).

A LDBEN de 1996 nos aponta, em termos legislativos que, o APD é previsto no âmbito da educação básica, sendo dever da área de Educação Especial oferecimento desse serviço no âmbito do Atendimento Educacional Especializado quando tratar do público-alvo da Educação Especial.

Uma questão que aparece na LDBEN e em documentos mais recentes, quando tratado das diretrizes do AEE, é sobre a formação necessária para o professor que atua na Educação Especial: todos os documentos afirmam que este deve ser um especialista. $\mathrm{Na}$ Política Nacional de Educação Especial na Perspectiva da Educação Inclusiva (SEESP/MEC, 2008) é ainda colocado que

\footnotetext{
Essa formação possibilita sua atuação no atendimento educacional especializado, aprofunda o caráter interativo e interdisciplinar da atuação nas salas comuns do ensino regular, nas salas de recursos, nos centros de atendimento educacional especializado, nos núcleos de acessibilidade das instituições de educação superior, nas classes hospitalares e nos ambientes domiciliares, para a oferta dos serviços e recursos de educação especial. (BRASIL. SEESP/MEC, 2008)
}

Não distante do exposto até aqui, na Resolução CNE/CEB nº 4 (BRASIL. CNE/CEB, 2009), no artigo 6 ${ }^{\circ}$, é reiterado que “Em casos de Atendimento Educacional Especializado 
em ambiente hospitalar ou domiciliar, será ofertada aos alunos, pelo respectivo sistema de ensino, a Educação Especial de forma complementar ou suplementar". Um fato que merece destaque é a diretriz que persiste nos documentos aqui apresentados de que o AEE, mesmo quando sob a modalidade de APD, é complementar e/ou suplementar ao ensino regular, não podendo ser substitutivo. Ou seja, dessa forma, com base nos documentos, compreendemos que o APD como é do escopo da educação básica deveria contar com o trabalho de um professor do ensino comum e um do ensino especializado, quando não houver a possibilidade de um trabalho em conjunto desses dois docentes, a responsabilidade do ensino desse educando não poderia ser somente do AEE.

Sobre as diretrizes para a oferta do APD, não encontramos referência alguma nos documentos legislativos e políticos mais atuais. Contudo, há um documento mais antigo que ao tratar do APD associado à classe hospitalar, descreve a organização e o funcionamento desse espaço educacional. O eixo do trabalho é compreendido pelos recursos e adaptações necessárias do espaço físico e de materiais para que o professor possa desenvolver o seu trabalho no ambiente domiciliar. Sendo que: "Estes recursos (instrumentos de apoio didático-pedagógico) e adaptações (eliminação de barreiras físicas e arquitetônicas, de acesso ao currículo, etc.) deverão possibilitar a igualdade de condições para o acesso ao conhecimento, assim como o acesso e a permanência na escola" (BRASIL. SEESP/MEC, 2002, p.16-17).

Não distante do eixo central do AEE, como sinalizado por Souza (2015), também a acessibilidade é o conceito norteador do trabalho desenvolvido na APD. Vale aqui destacar que a acessibilidade, no contexto da educação inclusiva, pode ser entendida pela transposição das barreiras arquitetônicas, atitudinais, sensoriais, entre outras, que comprometam a plena inserção do aluno com deficiência nas práticas do cotidiano escolar. Por isso, a proclamação da "mudança do meio", que enfatiza a construção de oportunidades para equalizar a participação dos alunos com deficiência nas práticas educacionais e sociais (BRASIL. CNE/CEBL, 2009; BRASIL. SECADI/MEC, 2015).

Em relação aos aspectos específicos da modalidade de atendimento domiciliar, ao tomarmos os documentos legais que sustentam o AEE, não encontramos alteração alguma em relação aos seus propósitos e objetivos gerais. Conforme o Decreto n. 7.611 (BRASIL, 2011), a “educação especial deve garantir os serviços de apoio especializado 
voltado a eliminar as barreiras que possam obstruir o processo de escolarização de estudantes com deficiência, transtornos globais do desenvolvimento e altas habilidades ou superdotação". Sendo, os objetivos do AEE:

I - prover condições de acesso, participação e aprendizagem no ensino regular e garantir serviços de apoio especializados de acordo com as necessidades individuais dos estudantes;

II - garantir a transversalidade das ações da educação especial no ensino regular;

III - fomentar o desenvolvimento de recursos didáticos e pedagógicos que eliminem as barreiras no processo de ensino e aprendizagem; e

IV - assegurar condições para a continuidade de estudos nos demais níveis, etapas e modalidades de ensino. (BRASIL, 2011)

Ainda nas diretrizes, é indicado que o AEE esteja institucionalizado e descrita sua forma de funcionamento no Projeto Político Pedagógico (PPP) da escola (CEB/CNE/BRASIL, 2009), prevendo na sua organização. Para tal, é indicada a elaboração do Plano de AEE, fundamental para o funcionamento deste serviço:

Art. 90 A elaboração e a execução do plano de AEE são de competência dos professores que atuam na sala de recursos multifuncionais ou centros de AEE, em articulação com os demais professores do ensino regular, com a participação das famílias e em interface com os demais serviços setoriais da saúde, da assistência social, entre outros necessários ao atendimento. (BRASIL. CBE/CNE, 2009)

Novamente, é reiterada a necessidade de, independente da modalidade, articulação da educação especial com o ensino regular para a organização da estrutura e do funcionamento do AEE.

\section{O Plano de AEE e o PEl: documentos condutores do trabalho do APD}

Para iniciarmos a discussão é necessário situarmos o Plano de AEE e o Plano Educacional Individualizado (PEI). Esses dois documentos são estratégias importantes para o processo de ensino-aprendizagem de alunos com deficiência matriculados em turmas comuns. Entretanto, a nosso ver, o PEI deveria ser utilizado não apenas para 
estudantes com deficiência do ensino regular, mas também para os que estão em classes e escolas especiais.

O Plano de AEE deverá ter descrito a identificação das necessidades educacionais específicas dos alunos, definição dos recursos necessários e das atividades a serem desenvolvidas (BRASIL. CNE/CEB, 2009). Nessa direção, ele tem como objetivo conhecer o sujeito nos diferentes ambientes, seu histórico, preferências, dificuldades, etc. A partir do Plano de AEE, os docentes poderão pensar o PEI do estudante, que consiste em

Planejamento individualizado, periodicamente avaliado e revisado, que considera o aluno em seu nível atual de habilidades, conhecimentos e desenvolvimento, idade cronológica, nível de escolarização já alcançado e objetivos educacionais desejados a curto, médio e longo prazos. Também são levadas em consideração expectativas familiares e do próprio sujeito. (GLAT, VIANNA, REDIG, 2012, p. 84)

O PEI é uma prática que não deve ser desvinculada do currículo da escola e série ou ano em que o aluno está matriculado. Então, é preciso ser pensado a partir de diversas vertentes e perspectivas: 1) dificuldades, habilidades, necessidades do aluno; 2) objetivos para a turma e para o sujeito em especial; 3) múltiplos olhares dos professores regentes, especialistas, coordenador pedagógico, família, demais profissionais e se possível do próprio aluno. Esse é um documento que deve ser elaborado de forma coletiva e colaborativa, no qual todos se responsabilizam pela sua execução.

O PEI é uma individualização e diferenciação do currículo, o qual conterá os conteúdos da série, estratégias com as metas a serem alcançadas e a avaliação do processo de construção do conhecimento. Portanto, o Plano de AEE e o PEI são documentos complementares, em que um respalda o outro, no que diz respeito à organização das metodologias, estratégias, objetivos e tempo que serão utilizados para o aprendizado do aluno em diferentes espaços e contextos na escola.

Para o APD é importante a elaboração de um PEI de acordo com o currículo da série do estudante, para que a partir dos objetivos traçados, o sujeito possa acompanhar os conteúdos da turma em que está matriculado. Entretanto, na presente pesquisa, como explicaremos mais adiante, a aluna estava matriculada em uma escola especial, então, o 
PEI e o Plano de AEE se misturam, pois nesse caso, não foi feito um PEI com a docente regente da turma. Como também não havia vínculo com o currículo da escola de origem, o PEI foi pensado de forma individualizada, customizada e diferenciada, de acordo com as necessidades, habilidades e contexto familiar, no qual a aluna está inserida. Esse distanciamento da escola faz com que a estudante e sua família fiquem excluídos dos acontecimentos acadêmicos da unidade escolar. Todavia, essa foi uma estratégia pedagógica que contribuiu para o funcionamento do AEE, além da implementação do programa individualizado de desenvolvimento escolar, oportunizando a "organização das intervenções educacionais junto aos alunos com deficiência" (AVILA, MONTEIRO, SILVA, 2015).

\section{O PEI como documento para a organização de um APD no escopo do AEE}

Neste estudo adotou-se a pesquisa qualitativa e, como metodologia, o estudo de caso. No desenvolvimento dos atendimentos pedagógicos domiciliares, foram adotados os pressupostos da pesquisa-ação (GLAT; PLETSCH, 2012), por meio da elaboração de um estudo de caso (ANDRÉ, 1995), com observação participante (FLICK, 2009).

Já o processo da análise dos dados ocorreu de forma constante durante o estudo, com base nos registros do diário de campo. Como indicado por Pletsch (2010), seguimos três etapas: a pré-seleção, exploração do material e interpretação dos dados. A primeira foi a organização dos dados, retomando aos objetivos da pesquisa; a segunda, organização dos dados de forma a indicar áreas temáticas e, a terceira, interpretação propriamente dita dos dados coletados.

O estudo teve como participante a aluna Samanta ${ }^{1}$, de 12 anos, com deficiência múltipla, envolvendo as áreas cognitiva e motora. A aluna, apesar de ainda não ter um diagnóstico fechado, apresenta indicativos da Síndrome de Dravet ou epilepsia mioclônica severa da infância ${ }^{2}$. O comportamento da aluna varia de acordo com os medicamentos que ingere e com a frequência das crises convulsivas que apresenta.

\footnotetext{
${ }^{1} \mathrm{O}$ nome da aluna nesse trabalho é fictício.

${ }^{2}$ Síndrome de origem genética que provoca convulsões na criança. Com isso, há uma regressão psicomotora associada a distúrbios comportamentais, agressividade e déficit cognitivo (LIBERALESSO, NASCIMENTO, KLAGENBERG, ZEIGEBOIM, JURKIEWICZ, 2015).
} 
A estudante frequentou uma escola especial, da rede pública, por um curto período de tempo e logo foi afastada por indicação médica, devido às suas condições de saúde. Dessa forma, a Secretaria Municipal de Educação, em 2013, encaminhou uma professora da Educação Especial para o APD.

O APD, no escopo do AEE, se desenvolveu, durante o período de 2013 a 2015, na residência da aluna, composta por apenas um cômodo, com participação da mãe, pai e irmã mais velha. Nessa direção, os atendimentos eram feitos com a colaboração de todos da família. Durante esse período, a família mudou três vezes de residência.

O APD, como já citado, é uma modalidade de atendimento para os alunos que estão impossibilitados de frequentar a escola regularmente, sendo assim, a princípio, o currículo a ser seguido deve ser o mesmo da turma e série correspondente. Porém, sabemos que na prática não é assim que acontece, principalmente por causa das condições em que o sujeito pode se encontrar. Por isso, é importante a existência de documentos que norteiem esse trabalho.

$\mathrm{Na}$ rede pública pesquisada, não há documentos próprios com diretrizes ou orientações para o oferecimento do APD, nem mesmo orientações específicas que tratem do AEE na modalidade domiciliar. Todo o serviço é pautado nas diretrizes gerais do AEE.

A nosso ver, apesar da modalidade domiciliar ser um desdobramento do AEE, os serviços são diferentes e acreditamos que há necessidade de organização e funcionamento diferenciados. Algumas práticas da sala de recursos podem ser utilizadas no APD, contudo, o objetivo do APD é diferente do traçado no AEE. Isso significa que no AEE são desenvolvidas atividades que despertam no alunado mecanismos de aprendizagem que facilitarão no acompanhamento dos conteúdos ensinados na sala de aula comum. Já o APD, é o único momento em que o educando tem acesso ao ensino de forma organizada com o professor. E, ainda, esse tempo é limitado, visto que, geralmente esse atendimento não acontece todos os dias como na escola. Cabe aqui destacar que no caso trazido para esse estudo, o APD no escopo do AEE era realizado, variando a frequência, entre 1 a 2 vezes por semana, 1 hora por dia (REDIG, 2015).

Outro aspecto diferenciador entre o APD e o AEE são os recursos pedagógicos. De acordo com Pacheco, Vieira e Pinheiro (2015) são utilizados como recursos pedagógicos 
do APD, teleaulas, computadores, jogos, etc. Porém, a aula ministrada em uma sala de recursos e a ministrada na residência do aluno são diferentes, principalmente, pelo fato de na maioria dos casos, o docente não ter acesso a esses materiais na casa do estudante. O atendimento ao aluno com deficiência na escola é planejado anteriormente a partir dos recursos disponíveis na sala, já no APD, o docente tem que levar o que deseja utilizar, e o deslocamento desses objetos pode ser complicado.

Sendo assim, o professor do APD precisa se organizar para utilizar materiais disponíveis na residência do aluno ou que consiga transportar, além de contar com os imprevistos do ambiente, como por exemplo, visitas, rotina do estudante, etc. Por isso, o PEI se torna um recurso potente para a organização do processo de escolarização do aluno em APD. Nesse caso, ainda mais, o planejamento da aula e o PEI precisam ser flexíveis, não só devido às necessidades do indivíduo, mas também por causa dos acontecimentos da rotina familiar (REDIG, 2015).

Dessa forma, o PEI além de ser um instrumento que auxilia na organização pedagógica do APD, tem a pretensão de garantir um currículo adaptado e personalizado para o aluno com deficiência. Partindo desse pressuposto, no atendimento pedagógico domiciliar, o PEI serve como um norteador das atividades a serem realizadas com o aluno.

No caso do PEI da aluna Samanta, foram necessários dois anos de coleta de dados para a elaboração do PEl. Apesar do trabalho ter sido iniciado no ano de 2013, esse instrumento apenas foi construído e, efetivamente aplicado, em 2015. Posto que, segundo Rocha e Avila (2015, p. 35), para a formulação do PEl é “importante o conhecimento das especificidades apresentadas por esses alunos, para que seus processos de aprendizagem possam ser de fato beneficiados, bem como mostraram ser importante compreender como podemos intervir e estimulá-los adequadamente”.

\section{A construção do PEI}

É importante ressaltar que o PEI foi construído em conjunto com a família e após uma entrevista inicial, o período de observação e de análise. A parceria entre família e professor de AEE é fundamental para o sucesso do trabalho pedagógico, principalmente, porque o processo de ensino-aprendizagem acontece na residência da aluna. 
Tabela 1: Tabela representativa para apresentar o PEI de Samanta (Fonte: as autoras, 2016)

\begin{tabular}{|l|l|}
\hline Características da aluna & $\begin{array}{l}\text { A aluna na maioria das vezes encontra-se agitada e agressiva; em } \\
\text { poucos momentos apresenta-se calma e apática. Apresenta } \\
\text { coordenação motora fina satisfatória, mas tem atenção limitada, } \\
\text { tem dificuldade para se comunicar e compreender o que foi dito. } \\
\text { Gosta de folhear livros. Ao mesmo tempo em que é agressiva, é } \\
\text { carinhosa. }\end{array}$ \\
\hline Potencialidades da aluna & $\begin{array}{l}\text { Demonstra potencialidade para a realização de atividades de vida } \\
\text { diária, como regar plantas, auxiliar na organização de objetos. }\end{array}$ \\
\hline Necessidades da aluna & $\begin{array}{l}\text { Desenvolver a comunicação, com o objetivo de tentar minimizar } \\
\text { os problemas comportamentais. Ampliar a sua compreensão } \\
\text { sobre regras e na realização de atividades de vida diária, com o } \\
\text { auxílio e supervisão, para que no futuro tenha autonomia. }\end{array}$ \\
\hline Estratégias & $\begin{array}{l}\text { Utilização de pranchas / cards de comunicação alternativa e e } \\
\text { ampliada. Realização de atividades simples como regar plantas, } \\
\text { jogar objetos no lixo, guardar objetos. Reconhecer imagens nos } \\
\text { livros e nos cards. }\end{array}$ \\
\hline Avaliação & $\begin{array}{l}\text { A avaliação será contínua, mas esse PEl foi pensado para o período } \\
\text { de um ano. }\end{array}$ \\
\hline
\end{tabular}

Durante a aplicação do PEI, a aluna apresentou melhoras na sua comunicação, porém os pais ainda não implementaram por completo a comunicação alternativa e ampliada $^{3}$ no seu cotidiano. De qualquer forma, iniciamos o reconhecimento de algumas imagens, como Coca-Cola, livro, pão, beijar, regar plantas e as fotos dos familiares e professora.

Nesse processo, a aluna começou a sinalizar o reconhecimento da foto do pai e da garrafa de Coca-Cola. Durante o trabalho ela entregava a ficha com a imagem da bebida, para então, receber um copo para beber. Ela já regava as plantas e ajudava na organização de objetos. Porém, como Samanta, apresentava muitas crises convulsivas, o seu aprendizado era lento, pois havia muitas recaídas, mas isso não significa que não houve avanços acadêmicos.

Dessa maneira, precisamos rever quais as oportunidades de aprendizagem que oferecemos para os sujeitos com comprometimentos graves e quais as expectativas e objetivos são traçados para o seu aprendizado e desenvolvimento. De acordo com Pletsch (2015, p. 23).

\footnotetext{
3 O conceito de comunicação alternativa e ampliada é contemplado pelas tecnologias assistivas que, segundo Pelosi (2011), consistem em recursos e serviços que são utilizados por pessoas de diferentes idades e níveis de comprometimento, seja este motor, sensorial, cognitivo ou de comunicação, buscando a melhor forma de substituir ou complementar essa dificuldade.
} 
as possibilidades de incorporação da cultura pelas pessoas com deficiência múltipla - especialmente aqueles que envolvem operações simbólicas - dependem das interações estabelecidas entre professor e aluno e/ou aluno e aluno durante as práticas pedagógicas, bem como dessas práticas em si e de suas condições concretas de vida (materiais, orgânicas e psicológicas). Portanto, para que possibilitem aos alunos com deficiência múltipla desenvolver novas formas de funcionamento mental, as atividades escolares devem priorizar o ensino dos conceitos, seus significados e sentidos.

Para essa mesma autora (PLETSCH, 2015), a apropriação do significado de palavras como "sim" e "não", já é o início para que sujeitos com deficiência múltipla consigam opinar sobre situações básicas do cotidiano, como escolher uma bebida. Esse é um exemplo da importância do aprendizado de um conhecimento não formal, mas essencial para o seu desenvolvimento e para a apropriação de outros conteúdos.

Souza (2013, p.233), ao tratar do processo de escolarização de um aluno com deficiência intelectual, apoiada na perspectiva histórico-cultural do desenvolvimento humano, ressalta a importância de "propostas pedagógicas desafiadoras, mas coerentes com as possibilidades perceptivas, sensitivas, de atenção, mnemônicas, cognitivas e motoras do aluno. Daí, a aprendizagem deverá resultar em novas formas/possibilidades de comportamento".

Vale salientar, que o APD deve ter como objetivo, também, a inclusão desse sujeito nas práticas cotidianas escolares, visto que, uma das características dessa modalidade é a individualização tanto do aprendizado quanto do ambiente. A individualização do ensino é um ponto positivo, pois é pensado de acordo com as necessidades do aluno, porém, ele não se beneficia do convívio com seus pares, como acontece na escola. Sendo assim, é preciso que o professor compreenda essa situação e proponha no $\mathrm{PEI}$, o retorno para a escola.

No caso de Samanta, essa opção ainda é remota, devido aos seus problemas de saúde, mas é necessário que haja a pretensão de inseri-la no contexto escolar. Nessa situação, o objetivo foi a inclusão nas atividades cotidianas da família e na vila onde reside. 
Outro ponto importante, no final do ano letivo de 2015: a aluna ampliou o reconhecimento das imagens trabalhadas e já apontava para os episódios de um desenho animado que gostaria de assistir e se concentrava para realizar as atividades propostas, mesmo que por pouco tempo. Esses exemplos foram grandes avanços no processo de ensino-aprendizagem de Samanta que, até o momento, não conseguia demonstrar a sua vontade sem um comportamento mais agitado e, em alguns casos, de forma agressiva.

Portanto, acreditamos que o trabalho sistematizado no PEI, auxiliou no progresso das relações tanto com a aluna quanto com seus familiares, que tinham ciência do que seria abordado nos atendimentos. A aluna, de alguma forma, conseguiu internalizar os dias das aulas, reforçado também por lembretes da mãe, o que resultava na espera da chegada da professora, pela Samanta, na porta da casa. A espera da aluna e o reconhecimento do que a docente faria ao chegar (Samanta entregava um livro), demonstra aprendizado e desenvolvimento significativos da discente diante dos conteúdos ensinados.

É importante ressaltar que o APD deve ser desenvolvido de maneira que a família possa contribuir para o aprendizado e desenvolvimento do estudante. Para tal, é preciso que o professor guie a família para essa mudança de olhar, de maneira, que perceba que esse momento é fundamental para a constituição da autonomia do sujeito e construção de conhecimento.

O PEl, além de se configurar como um recurso que orienta o trabalho do docente, também é um esclarecimento para a família das necessidades e potencialidades da estudante. Em outras palavras, mostra que, apesar de todas as dificuldades apresentadas por Samanta e salientadas pelos médicos e por seus comportamentos, ela é capaz de aprender.

Nessa pesquisa, foram priorizadas atividades que auxiliem no cotidiano e no seu relacionamento com as demais pessoas, mesmo que não enfatizassem conteúdos acadêmicos tradicionais, como a alfabetização, por exemplo. Sendo assim, é fundamental compreender que a construção de conhecimento se dá no dia a dia, nas relações interpessoais e na mediação da aprendizagem. De acordo com Vieira e Monteiro (2014, p.100), 
é necessário que se mude a maneira de olhar para o sujeito com deficiência. Que se pense, não em avaliar o que ele sabe ou não sabe, mas em como acrescentar conhecimentos àquilo que ele já aprendeu. É necessário dar sentido ao que está sendo proposto e tornar significativas as ações do sujeito.

\section{Considerações}

O primeiro ponto ao qual chamamos atenção, ao olharmos para o escopo das diretrizes e dos processos pedagógicos, é a falta de conexão entre o trabalho do professor do AEE no escopo do APD. No caso aqui relatado, a situação parece ter sido agravada pelo fato de a aluna estar matriculada em uma escola especial da rede pública, mas que não há um currículo organizado de forma coletiva como eixo de estrutura do trabalho pedagógico da instituição. Ademais, a falta de diretrizes e orientações locais do município, acabam por deixar a cabo das condições de trabalho do docente (formação, disponibilidade, condições materiais, comprometimento, etc.) para o desenvolvimento do trabalho.

Vale lembrar que o trabalho desenvolvido no APD é diferente do realizado na sala de recursos, pelo $A E E$. Ambos os serviços têm propostas divergentes: enquanto o APD tem como objetivo a escolarização do aluno, o AEE pretende complementar ou suplementar o aprendizado. Por isso, reforçamos a ideia de um trabalho colaborativo entre professores de turma comum, como possíveis docentes de APD e AEE, com a finalidade de atender as demandas específicas do educando e do próprio atendimento.

O professor do APD deve trabalhar de forma colaborativa não só com os demais docentes da escola na qual o aluno está matriculado, mas também com a família, principalmente no caso de Samanta, em que a residência só possuía um cômodo, ou seja, todos participavam ativamente do atendimento pedagógico. No caso da Samanta, como explicado anteriormente, pelo fato de estar matriculada em uma escola especial, a relação com a professora de sua turma era distante, exatamente pelo currículo ser individualizado tanto no APD (em especial para Samanta) quanto nas instituições especializadas. 
A organização e funcionamento do APD não são simples, pois envolvem diversos fatores e atores que vão além do pedagógico. O trabalho do APD contempla as relações familiares, uma vez que a escolarização acontece na residência do aluno, por isso é fundamental em que haja um ambiente adequado para que o estudante e a família entendam que aquele momento é reservado para o estudo (REDIG, 2015). Outro aspecto é a relação do docente com a escola de origem do aluno, ou seja, deve haver um contato constante dos professores da turma com o de AEE para a troca de ideias, conteúdos, bem como pensar na avaliação contínua do educando por toda a equipe escolar. Essa parceria vale também para a participação nos conselhos de classe, com a finalidade da reflexão e discussão do desenvolvimento acadêmico do estudante (SILVA, PACHECO, PINHEIRO, 2014; PACHECO, VIEIRA, PINHEIRO, 2015; REDIG, 2015). É fundamental a parceria com os demais profissionais envolvidos com o sujeito, como os médicos, por exemplo, visto que eles influenciam diretamente na melhoria da condição de saúde do indivíduo do atendimento na modalidade domiciliar. Portanto, é preciso tecer uma rede de parcerias para que o trabalho realizado no APD tenha resultados significativos no desenvolvimento acadêmico, social e pessoal do alunado.

Redig (2015) pontua também que é necessário repensar a formação do docente para o APD, visto que, no município pesquisado, esse atendimento é desenvolvido por profissionais da Educação Especial, do AEE. Sendo assim, são professores com formação em magistério e capacitações na área. Entretanto, muitos alunos atendidos na modalidade domiciliar não são alunos público-alvo da Educação Especial, mas sim, apresentam uma condição de saúde que os impedem de frequentar a escola. Portanto, na maioria dos casos, o currículo será o mesmo da sua série e turma, ou seja, será necessário o ensino de matérias acadêmicas como biologia, línguas, etc., que fogem do campo de conhecimento do docente especialista, sendo um trabalho diferente do desenvolvido na sala de recursos. Então, é fundamental se repensar na formação tanto do professor da Educação Especial quanto do ensino básico para atender essa demanda e que a responsabilidade de lecionar nessa modalidade não seja apenas do AEE.

Formação que promova o desenvolvimento de aspectos sensíveis para as relações humanas e a compreensão da realidade familiar e social em que o aluno atendido está inserido. Ceccim e Fonseca (1998, p. 26) apontam a 
necessidade do professor de atendimento pedagógico especializado (aqui contemplando também o atendimento hospitalar) atuar com "planos e programas abertos, móveis, mutantes, constantemente reorientados pela situação especial e individual de cada criança e adolescente sob atendimento". (REDIG, 2015, p. 63)

Nesse sentido, percebemos a importância da elaboração do PEl como recurso para organização e funcionamento do AEE no escopo do APD, de forma a atender as necessidades e potencialidades do aluno, visto que é por meio desse instrumento que podemos ofertar um ensino significativo para esses educandos. A escolarização de pessoas com deficiência, independente do espaço de aprendizagem, é fundamental para garantir o direito desses sujeitos ao ensino e à construção de conhecimento.

\section{Referências}

ANDRÉ, Marli. Eliza Dalmazo Afonso. Etnografia da prática escolar. Campinas: Papirus, 1995.

AVILA, Leila Lopes de; MONTEIRO, Aline Hygino Carvalho; SILVA, Ana Lúcia da Conceição. A construção do planejamento educacional individualizado: a experiência de uma escola da rede municipal de Educação de Belford Roxo/RJ. In: PLETSCH, Márcia Denise; SOUZA, Flávia Faissal de. (Orgs.). Observatório de educação especial e inclusão escolar: balanço das pesquisas e das práticas na Baixada Fluminense. São Carlos: Marquezine \& Manzini: ABPEE, 2015. p. 99-112.

BRASIL. Constituição da República Federativa do Brasil. Brasília: Senado Federal, 1988.

BRASIL. Ministério da Educação e Cultura. Lei de diretrizes e bases da Educação Nacional, n. 9394. Brasília: MEC, 1996.

BRASIL. Decreto n. 7.611, de 17 de novembro de 2011. Dispõe sobre a educação especial, o atendimento educacional especializado e dá outras providências. Diário Oficial da União, Brasília, 18 de novembro de 2011.

BRASIL. Conselho Nacional de Educação. Câmara de Educação Básica. Resolução Conselho Nacional de Educação / Câmara de Educação Básica n. 2, de 11 set. 2001: Institui diretrizes nacionais para a Educação Especial na Educação Básica. Diário Oficial da União, Brasília, 14 de setembro de 2001. 
BRASIL. Conselho Nacional de Educação. Câmara de Educação Básica. Resolução Conselho Nacional de Educação / Câmara de Educação Básica n.4, de 2 outubro de 2009: Institui diretrizes operacionais para o Atendimento Educacional especializado na Educação Básica, modalidade Educação Especial. Diário Oficial da União, Brasília, 5 de outubro de 2009.

BRASIL. Secretaria de Educação Continuada, Alfabetização, Diversidade e Inclusão. Orientações para implementação da política de educação especial na perspectiva da educação inclusiva. Brasília: Mec/Secadi, 2015.

BRASIL. Secretaria de Educação Continuada, Alfabetização, Diversidade e Inclusão. Política nacional de educação especial. Brasília: Mec/Seesp, 1994.

BRASIL. Secretaria de Educação Continuada, Alfabetização, Diversidade e Inclusão. Classe hospitalar e atendimento pedagógico domiciliar: estratégias e orientações. Brasília, DF: Mec/Seesp, 2002.

BRASIL. Secretaria de Educação Continuada, Alfabetização, Diversidade e Inclusão. Política Nacional de educação especial na perspectiva da educação inclusiva. Brasília: Mec/Seesp, 2008.

FLICK, Uwe. Introdução à pesquisa qualitativa. 3. ed. Porto Alegre: Artmed, 2009.

GLAT, Rosana; PLETSCH, Márcia Denise. Inclusão escolar de alunos com necessidades especiais. 2. ed. rev. Rio de Janeiro: Eduerj, 2012.

GLAT, Rosana; VIANNA, Márcia Marin; REDIG, Annie Gomes. Plano Educacional Individualizado: uma estratégia a ser construída no processo de formação docente. Ciências Humanas e Sociais em Revista, v. 34, n. 12, p. 79-100, 2012.

LIBERALESSO, Paulo Breno Noronha; NASCIMENTO, Lincoln Francisco do; KLAGENBERG, Karlin Fabianne; ZEIGELBOIM, Bianca Simone; JURKIEWICZ, Ari Leon. Epilepsia mioclônica severa da infância. 2008. Disponível em: <http://www.neuropediatria.org.br/index.php?option=com_content\&view=article\&id=147 :artigo-do-mes\&catid=54:artigo-do-mes>. Acesso em: 1 jun. 2015.

PACHECO, Mirna Cristina Silva; VIEIRA, Sheila Venancia da Silva; PINHEIRO, Vanessa Cabral da Silva. Um olhar sobre o Atendimento Pedagógico Domiciliar: políticas e práticas educacionais. In: PLETSCH, Márcia Denise; SOUZA, Flávia Faissal de. (Orgs.). Observatório de Educação Especial e inclusão escolar: balanço das pesquisas e das práticas na Baixada Fluminense. São Carlos: Marquezine \& Manzini: ABPEE, 2015. p. 137-148.

PELOSI, Miriam. Pesquisas em Comunicação Alternativa no Brasil: Participação da Universidade Federal do Rio de Janeiro. In: NUNES, L. R. O. de P.; PELOSI, M. B.; WALTER, C. C. de F. (Org.). Compartilhando Experiências: ampliando a comunicação Alternativa.Marília: Abbpee, 2011. v. 01, p. 125-138. 
PLETSCH, Márcia Denise. Repensando a inclusão escolar: diretrizes políticas, práticas curriculares e deficiência intelectual. Rio de Janeiro: Editoras Nau; Edur, 2010.

PLETSCH, Márcia Denise. Deficiência múltipla: formação de professores e processos de ensino-aprendizagem. Cadernos de Pesquisa, v. 45, n.155. p.12-29, jan./mar., 2015.

REDIG, Annie Gomes. Atendimento educacional especializado na modalidade domiciliar: um estudo de caso. Cadernos de Pesquisa, v. 22. , p. 59-70, 2015.

ROCHA, Maíra Gomes de Souza da; AVILA, Leila Lopes de. Pesquisas, práticas e experiências sobre os processos de ensino e aprendizagem de alunos com deficiência intelectual e múltipla em escolas públicas da Baixada Fluminense. In: PLETSCH, Márcia Denise; MENDES, Geovanna Mendonça Lunardi; HOSTINS, Regina Célia Linhares. (Orgs.). A escolarização de alunos com deficiência intelectual: políticas, práticas e processos cognitivos. São Carlos: Marquezine \& Manzini: ABPEE, 2015. p. 31-46.

SILVA, Sheila; PACHECO, Mirna; PINHEIRO, Vanessa. Reflexões sobre o atendimento pedagógico domiciliar. In: SEMINÁRIO INTERNACIONAL DE INCLUSÃO ESCOLAR: PRÁTICAS EM DIÁLOGO. CAp-UERJ, 21 a 23 de outubro de 2014. Anais I Seminário Internacional Inclusão Escolar: práticas em diálogo. Rio de Janeiro: CAp-UERJ, 2014. 1-10.

SOUZA, Flávia Faissal de. Politicas de educação inclusiva: análise das condições de desenvolvimento dos alunos com deficiência na instituição escolar. 2013. Tese (doutorado em educação (Psicologia Educacional)) - Universidade Estadual de Campinas, Campinas 2013.

SOUZA, Flávia Faissal de. Atendimento educacional especializado: das diretrizes políticas à escolarização dos alunos com deficiência intelectual no ensino fundamental. 2015. Relatório do Estágio Pós-Doutoral (Educação) - Universidade Federal Rural do Rio de Janeiro, Nova Iguaçu, 2015.

VIEIRA, Soraia da Silva Pedroso; MONTEIRO, Maria Inês Bacellar. A autonomia do sujeito com deficiência intelectual: possibilidades e impossibilidades vivenciadas no cotidiano da escola. In: MONTEIRO, Maria Inês Bacellar; FREITAS, Ana Paula de; CAMARGO, Evani Andreatta Amaral. (Orgs.) Relações de ensino na perspectiva inclusiva: alunos e professores no contexto escolar. Araraquara, SP: Junqueira \& Marin, 2014. p. 83-110.

Recebido em: 30/03/2016 Aprovado em: 11/04/2016

Universidade do Estado de Santa Catarina - UDESC Programa de Pós-Graduação em Educação - PPGE 